\title{
Noise annoyance from different sources in young adults
}

\author{
Lubica Argalasova ${ }^{1 *}$, Alexandra Filova ${ }^{1}$, Katarina Hirosova ${ }^{1}$, Diana Vondrova $^{1}$, \\ Martin Samohyl ${ }^{1}$, Ludmila Sevcikova ${ }^{1}$ and Jana Jurkovicova ${ }^{1}$ \\ ${ }^{1}$ Institute of Hygiene, Faculty of Medicine, Comenius University, Spitalska 24, 81372 Bratislava, \\ Slovakia
}

\begin{abstract}
The aim of the study is to evaluate the adverse effects of community noise on health and the response to noise exposure in residential areas of Bratislava. The study quantifies the exposure to different environmental noise sources as well as the social noise exposure in the sample of university students. The validated methodology according to ICBEN and the Ohrkan study was used. The measurement of ambient noise levels was done using hand-held sound level analyzer. There were 837 university students ( 256 males), average age $23.09 \pm 2.23$, enrolled into the study so far; 267 in the housing facility exposed to road traffic noise $\left(L_{A e q}=67.6 \mathrm{~dB}\right)$ and 570 in the control one $\left(L_{A e q}=53.4 \mathrm{~dB}\right)$. From the total sample $79.2 \%$ students reported the use of personal music players (PMP) in the last week in the average time of 293 minutes. There was a significant difference between the duration and frequency of listening to PMP between the exposed and the control group. There was not significant difference between the duration of time spent at activities with high noise exposure. The results of the study showed the importance of road traffic noise and the social noise for health as well and the need for a preventive action.
\end{abstract}

\section{Introduction}

Community noise constitutes an integral part of environmental pollution and has a great negative impact, especially in populations living in urban areas. Although the physiological and non-physiological adverse effects of noise are well documented nowadays, there is a need of more research and solutions, as noise pollution continues to rise [1].

Community noise is considered to be emitted from all the sources, apart from industrial facilities. The major sources of community noise affecting daily human activities and wellbeing are road traffic, railway and neighborhood noise. During the last decades, environmental studies and research being progressively carried out are undoubtedly proving the undesirable impact of noise in health and quality of life $[1,2,3,4]$.

\footnotetext{
* Corresponding author: lubica.argalasova@,fmed.uniba.sk
} 
In the European Union, about 56 million people (54\%) living in areas with more than 250000 inhabitants are exposed to road traffic noise of more than average $L_{D E N}$ (dayevening-night) $55 \mathrm{~dB}$ per year, which is thought to be risky to health [5]. WHO estimated that in high-income western European countries (population about 340 million people), at least 1 million healthy life years are lost every year (DALY - disability-adjusted life-years) because of environmental noise [6].

Hearing impairment, annoyance, sleep disturbance and cardiovascular diseases are among the most common adverse health effects of community noise, posing a great growing concern. In spite of the numerous scientific studies and counter-measures to control and eliminate noise pollution, this public health problem continues to grow, presumably due to the advent of a more modernized way of life nowadays [4].

The aim of this study is to evaluate the adverse effects of community noise on health and the response to noise exposure in residential areas of Bratislava, Slovakian capital. The study quantifies the exposure to different environmental noise sources as well as the social noise exposure (personal music players, events with high noise exposure) in the sample of university students aged 19-25 years.

\section{Material and methods}

The research was conducted at the Institute of Hygiene Medical Faculty Comenius University in Bratislava. The validated methodology according to ICBEN and the Ohrkan study was used $[7,8]$. The measurement of ambient noise levels was done using hand-held sound level analyzer.

\subsection{Exposure assessment}

Maximal, minimal and equivalent sound levels were assessed for both the control and exposed groups living in the Slovakian capital Bratislava by hand-held analyzer Brüel\&Kjaer type 2250, with sound level meter software BZ-7222 and frequency analysis software from Brüel\&Kjaer. Exposed housing facility is a student dormitory, situated near the major transportation route, the main thoroughfare with railway transport; control housing facility is a student dormitory in a quiet area with surrounding greenery. All measurements were recorded according to the valid legislation during the time intervals from 17.00-18.00 and from 20.00-21.00 in the exposed and at the same time in the control area. This time interval was chosen to record the afternoon traffic peak and to detect the time most annoying for students and for their activities (studying, watching TV, talking, and falling asleep). Measurements were recorded during spring period at working days (Tuesday) two times on each site. Road traffic flow composition was assessed as well.

\subsection{Sample}

There were 837 university students ( 256 males), average age $23.09 \pm 2.23$, enrolled into the study so far; 267 in the housing facility exposed to road traffic noise and 562 in the control one in Bratislava. Students significantly did not differ by gender, but they differed by age (older in the control area), flat location in relation to noise exposure, position of a flat in the floor height, length of stay in the given area, windows orientation, windows types and satisfaction with flat surrounding. The respondents have been living in the given area at least for four years. 


\subsection{Noise annoyance questionnaire}

Subjective response was assessed by the authorized "Noise annoyance questionnaire", the different sources of environmental noise were quantified [9].The validated 5 grade noise annoyance verbal scale (Not at all; Slightly; Moderately; Very; Extremely), was developed and recommended by experts from the noise research ICBEN (The International Commission on the Biological Effects of Noise) team [7].

The questionnaire comprised personal (age, gender, education), behavioral (smoking, coffee and alcohol consumption), and questions focused on the characteristics of residential environment (localization, construction and surrounding of residential buildings, the location and amenities of the apartment, window orientation to quiet and noisy streets and the length of stay in the apartment). It also included questions on possible non-auditory health effects (noise annoyance from different sources, interference with various activities and sleep disturbance) and subjective assessment of health troubles (headache, nervousness and irritability, difficulties falling asleep, the use of different types of medications, the presence of cardiovascular diseases and overall assessment of the health status). A special section is dedicated to traffic noise annoyance and its psychological and physiological effects as well as the social noise exposure (personal music players (PMP), events with high noise exposure). The intensity and duration of exposure was subjectively assessed, as well as the type of headphones. At the end, we ask whether respondents have complained on noise annoyance and disturbance and about the corrective actions implemented in the house to reduce noise exposure. Information from respondents was obtained by personal interview. Response rate of the questionnaire was $90 \%$.

Social noise exposure was quantified by subjective assessment of intensity and frequency of listening to personal music players and the duration of time spent at activities with high noise exposure - playing the music instrument, visiting cinema, classical, rock, pop, jazz concerts, discotheques, entertainment facilities, sport events, noisy household and garden work). The authorized methodology was based on the Ohrkan study [8]. The duration and frequency of PMP listening were assessed in the course of one week, as well as the loudness level and the type of headphones (headset, earphones, earbuds). The duration of time (hours and minutes per week or month) spent at activities with high noise exposure - entertainment facilities, discotheques, concerts of different music styles (classic, rock, pop, jazz), sport activities, playing the music instrument and noisy household and garden work was assessed subjectively as well.

\subsection{Statistical analysis}

Statistical evaluation comprises the methods of descriptive statistics, the relationship between continuous variables were examined by bivariate analysis, t-test, analysis of variance (ANOVA) and correlation coefficients. Relationships between categorical data were evaluated by contingency tables, chi-square test and stratified analysis. Statistical packages Epi Info ${ }^{\mathrm{TM}}$, Version 7.1.1.1, 2013 and SPSS, 2016 were implemented.

\section{Results}

The monitoring of sound levels in the exposed area showed the levels above the national and international limits in the afternoon and in the evening time interval (17.00-18.00 and 20.00-21.00) $[3,5,10]$. Sound levels in the control area were significantly lower 
$(p<0.001)$. The higher sound levels in the evening interval could be due to other noise sources (e.g. entertainment facilities) (Table 1, 2).

In the composition of the traffic flow, the number of passenger cars and trams, which are considered to be particularly annoying, was predominant. In the composition of the traffic flow in the control area the number of passenger cars was also predominant, however; not in such numbers as in the exposed area; there were buses and lorries, but no trams (Table 1, 2).

The indicators estimated from Bratislava strategic noise map were $L_{D E N}=66 \pm 2 \mathrm{~dB}$ vs $L_{D E N}=56 \pm 4 \mathrm{~dB}(p<0.05)($ http://www.laermkarten.de/bratislava/) [11].

Table 1. Sound levels in the exposed housing facility, April 2016.

\begin{tabular}{|l|c|c|c|c|}
\hline Time intervals & $\begin{array}{c}\text { Sound level } \\
\left.\boldsymbol{L}_{\boldsymbol{A} \min } \mathbf{( d B}\right)\end{array}$ & $\begin{array}{c}\text { Sound level } \\
\boldsymbol{L}_{\boldsymbol{A} \max }(\mathbf{d B})\end{array}$ & $\begin{array}{c}\text { Sound level } \\
\boldsymbol{L}_{\boldsymbol{A} \text { eq }}(\mathbf{d B})\end{array}$ & $\begin{array}{c}\text { Road traffic flow } \\
\text { composition }\end{array}$ \\
\hline $17.00-18.00$ & 58.6 & 75.5 & 67.5 & A 5460, B 36, L 60, T 72 \\
\hline $20.00-21.00$ & 52.1 & 81.3 & 66.9 & A 4644, B 12, L 12, T 60 \\
\hline
\end{tabular}

Legend: A - automobile, B - bus, L - lorry, T - tram

Table 2. Sound levels in the control housing facility, April 2016.

\begin{tabular}{|l|c|c|c|l|}
\hline Time intervals & $\begin{array}{c}\text { Noise level } \\
\boldsymbol{L}_{\boldsymbol{A} \min }(\mathbf{d B})\end{array}$ & $\begin{array}{c}\text { Noise level } \\
\boldsymbol{L}_{\boldsymbol{A} \max }(\mathbf{d B})\end{array}$ & $\begin{array}{c}\text { Noise level } \\
\boldsymbol{L}_{\text {Aeq }}(\mathbf{d B})\end{array}$ & $\begin{array}{c}\text { Road traffic flow } \\
\text { composition }\end{array}$ \\
\hline $17.00-18.00$ & 41.5 & 68.3 & 50.4 & A 108, B 12, L 0, T 0 \\
\hline $20.00-21.00$ & 41.7 & 69.9 & 53.6 & A 60, B 12, L 0, T 0 \\
\hline
\end{tabular}

Legend: A - automobile, B - bus, L - lorry, T - tram

Students in the exposed housing facility were significantly more annoyed by road traffic noise $\left(O R_{M H}=3.14,95 \% C I=2.66-3.71\right)$, by railways noise (trams) $\left(O R_{M H}=1.43,95 \%\right.$ $C I=1.19-1.72)$, noise from industry $\left(O R_{M H}=1.72,95 \% C I=1.45-2.03\right)$, noise from neighborhood $\left(O R_{M H}=1.45,95 \% C I=1.24-1.69\right)$. There was no significant difference concerning noise annoyance from entertainment facilities $\left(O R_{M H}=0.90,95 \%\right.$ $C I=0.73-1.12$ ), house construction and aircraft noise (Table 3 ).

Table 3. Annoyance risks from different community noise sources (year 2016).

\begin{tabular}{|l|c|}
\hline $\begin{array}{l}\text { Noise annoyance } \\
\text { (type of noise) }\end{array}$ & Risks in 2016 \\
\hline Road traffic & $\boldsymbol{O R}(\mathbf{9 5} \% \mathbf{C I})$ \\
\hline Neighborhood & ${ }^{+} 3.14(2.66-3.71)^{* * *}$ \\
\hline Entertainment facilities & ${ }^{+} 1.45(1.24-1.69)^{* * *}$ \\
\hline House construction & ${ }^{+} 0.90(0.73-1.12)$ \\
\hline Railways & ${ }^{+} 0.99(0.80-1.22)$ \\
\hline Aircraft & ${ }^{+} 1.43(1.19-1.72)^{* * *}$ \\
\hline Industry ${ }^{* *}$ & $0.91(0.71-1.16)$ \\
\hline \multicolumn{2}{|l|}{ Legend: ${ }^{* * *} p<0.001,+$ Mantel-Haenszel weighted odds ratio } \\
\multicolumn{2}{|c|}{$C I=$ confidence interval; $O R=$ odds ratio } \\
\hline
\end{tabular}


From the total sample of respondents, 658 (79.2\%) students reported listening to PMP in the last week for the average time of 293 minutes. There was a significant difference in PMP use between the exposed $(85.3 \%)$ and the control group $(76.5 \%)(p=0.003)$ and also in the duration of listening to PMP in minutes $(333 \pm 390$ vs $272 \pm 362)(p<0.05)$, but it was not significant between genders $(p=0.21)$.

More than $14 \%$ of students listen to the music on the loudness level 4 (they cannot hear the speech or even the traffic) and more than $80 \%$ (85.14) use earbuds. There was not significant difference between the loudness level of PMP or in the duration of time spent at most events with high noise exposure between the exposed and control group.

The significant difference was in the type of headphones; earbuds are more often used by students from the exposed area (more than $90 \%$ of students) $(p=0.02)$. Ear bud insert phone types are more harmful according to SCENIHR (2008) and increase the sound level by $7-9 \mathrm{~dB}[12]$.

The presence of subjective hearing impairment of PMP users was significantly higher $(25 \%)$, than in the non-PMP users $(18 \%)(p<0.05)$.

From activities with high intensity of noise exposure most students took part in household and garden work $(n=438)$, where they spent on average $447 \pm 689$ minutes. The second most frequent activity was visiting a cinema $(n=374)$, where students spent on average $194 \pm 379$ minutes per month. The third one was visiting discotheques $(n=300)$ where they spent on average $457 \pm 661$ minutes per month. The fourth most preferred activity was the visit of rock concerts $(n=146)$, where respondents spent on average $244 \pm 368$ minutes per month. Most of the time, subjects $(n=143)$ devoted to sport events, where they spent on average $479 \pm 760$ minutes per month. Students spent $459 \pm 642$ minutes playing musical instrument $(n=125), 129 \pm 107$ minutes visiting classical music concerts $(n=59)$ and $303 \pm 350$ minutes in sport shooting $(n=11)$ (Fig. 1).

Students from the exposed group to road traffic noise spent at the cinema about $244 \pm 650$ minutes per month, compared with subjects in the control group who spent in the cinema on average $170 \pm 98$ minutes per month $(p=0.08)$. There was no significant difference between the duration of time spent at the other events with high noise exposure between the exposed and the control group.

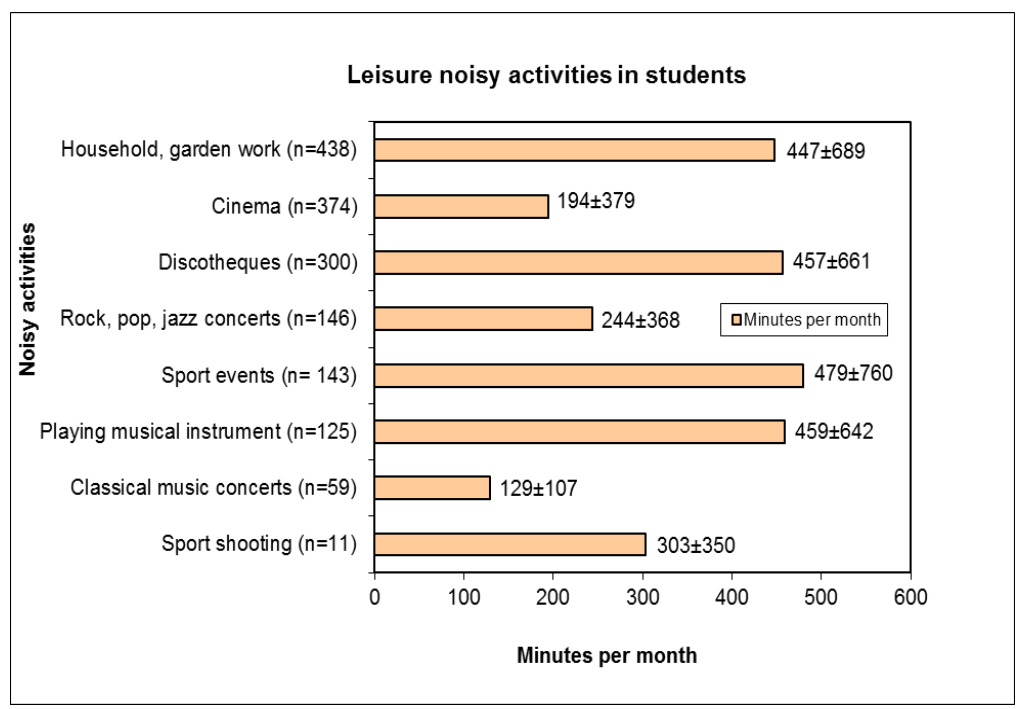

Fig. 1. Leisure noisy activities in the sample of university students. 


\section{Discussion}

Our findings confirmed that students in the exposed housing facility were significantly more annoyed by road traffic noise, by railways noise (trams), but also noise from the other sources such as industry and neighbourhood. No significant difference concerning noise annoyance from entertainment facilities was probably due to similar exposure (and very high) in both student dormitories.

Results are consistent with the findings of other studies reporting $88-90 \%$ of teenagers and young adults listening to PMPs through earphones [13]. A number of papers published recently estimated the risk of hearing loss due to the use of PMPs, as well as the actual incidence of hearing loss and tinnitus in the exposed populations. The studies were carried out in German, American, Italian, Dutch, Slovenian, Brazilian, and Malaysian teenagers and young adults $[14,15,16,17,18,8,19]$.

The percentage of teenagers and young adults at risk of developing noise induced hearing loss (NIHL) was estimated to be between 17\% and almost 29\% [13].

In our study, university students in the group exposed to road traffic noise were listening to PMP more often and with higher duration than students from the control group (possibly trying to mask the effect of this environmental noise source). However, the level of loudness in PMP listening was not significant between groups. The duration of time spent at the other events with high noise exposure was not significant between groups. These results are difficult to compare with the results of the other studies, because we are not aware of a study which has been studying such associations by now.

In the future, we would like to enlarge our study sample and to add a population group of adolescents in the age group of 15-19 years. In cooperation with the ENT experts we would like to perform audiometric, tympanometric and other objective examinations to determine hearing loss and to objectify the effects of social noise exposure on the hearing organ. Within the quantification of the environmental noise effects, we will explore the risk of chronic diseases in more detail in teenagers and in the young adults.

\section{Conclusion}

Results confirmed risk effect of road traffic noise on the young population. In our study $79.2 \%$ of respondents reported listening to personal music players (PMP) in the last week for the average time of 293 minutes. There was a significant difference between the frequency and duration of listening to PMP in the groups of respondents with a different road traffic noise exposure. There was no significant difference between the duration of time spent at events with high noise exposure in the exposed and in the control group.

The results of the study showed the importance of road traffic noise and the social noise as well for health and well-being. After the finalization of the study results, we would like to formulate the proposals and interventional procedures and effectively target the preventive measures (education, the use of noise-cancelling headphones for PMP users) in the vulnerable groups of teenagers and young adults and their parents and teachers as well.

The research was partially supported by a grant Y.A.B.S. (Youth and Parents Behavioral Survey in Slovakia) O-15-101-/0001-00 


\section{References}

1. E. Murphy, E.A. King, Environmental noise pollution. Noise mapping, Public health, and Policy (Elsevier, 2014)

2. S. Žiaran, Low-frequency noise and vibration (Slovak Technical University, Bratislava, 2016)

3. B. Berglund, T. Lindvall, DH Schwela DH (eds), Guidelines for Community Noise (WHO, Geneva, 2000)

4. L. Fritschi, L.A. Brown, R. Kim, D. Schwela, S. Kephalopoulos (eds), Burden of disease from environmental noise. Quantification of healthy life years lost in Europe (WHO, Geneva, 2011)

5. Ch. Hurtley (ed), Night noise guidelines for Europe (WHO, Geneva, 2009)

6. M. Basner, W. Babisch, A. Davis, M. Brink, C. Clark, S. Janssen, S. Stansfeld, Lancet 383, 9925 (2014)

7. J.M. Fields, R.G. de Jong, T. Gjestland, I.H. Flindell, R.F.S. Job, S. Kurra, P. Lercher, M. Vallet, T. Yano, R. Guski, U. Felscher-Suhr, R. Schumer, J. Sound Vib. 242, 4 (2001)

8. D. Twardella, C. Perez-Alvarez, T. Steffens, G. Bolte, H. Fromme, U. Verdugo-Raab, Noise Health 15, 67 (2013)

9. L. Sobotova, J. Jurkovicova, J. Volekova, L. Aghova L, IJOMEH 14, 2 (2001)

10. Slovak Ministry of Health Decree No. 549/2007

11. EUROAKUSTIK: Web page Strategic noise maps, accessed on 6 March 2017: http://www.hlukovamapa.sk/strategicka-hlukova-mapa-bratislavskej-aglomeracie.html

12. SCENIHR, Potential health risks of exposure to noise from personal music players and mobile phones including a music playing function (Scientific Committee on Emerging and Newly Identified Health Risks, European Commission, Brussels, 2008)

13. M. Basner, M. Brink, W. Bristow, Y. de Kluizenaar, L. Finegold, J. Hong, S.A. Janssen, R. Klaeboe, T. Leroux, A. Liebl, T. Matsui, D. Schwela, M. SliwinskaKowalska, P. Sörqvist, Noise Health, 17, 75 (2015)

14. I. Vogel, H. Verschuure, C.P.B. van der Ploeg, J. Brug, H., Am J. Public Health, 100, 6 (2010)

15. R.R. Figueiredo, A.A. Azevedo, P.M. Oliveira, S.P. Amorim, A.G. Rios, V. Baptista, Braz J Otorhinolaryngol, 77, 3 (2011)

16. C.D.F. Portnuff, B.J. Fligor, K.H. Arehart, Int. J. Audiol. 52 (2013)

17. E. Pellegrino, C. Lorini, G. Allodi, C. Buonamici, G. Garofalo, G. Bonaccorsi, Ann. Ig. 25, 5 ( 2013)

18. D.C. Colon, U.Verdugo-Raab, C.P.Alvarez, T. Steffens, S.C. Marcrum, S. Kolb, C. Herr, D. Twardella, Noise Health 18, 85 (2016)

19. S. Jeram, N. Delfar, 11 th International Congress on Noise as a Public Health Problem (ICBEN) (Nara, JAPAN, 2014) 